Imágenes en cardiología

\title{
Ecocardiografía transesofágica tridimensional en la evaluación, guía y seguimiento de intervenciones cardíacas percutáneas.
}

Luigi Gabrielli ${ }^{1,2}$, Carlos Brambila ${ }^{1}$, Rocío Robles ${ }^{1}$, Silvia Montserrat ${ }^{1}$, Bárbara Vidal ${ }^{1}$, Manel Azqueta ${ }^{1}$, Marta Stiges $^{1}$, Carles Paré ${ }^{1}$.

1 Laboratorio de Cardiología, Hospital Clínic, Barcelona, España.

2 Pontificia Universidad Católica de Chile, Santiago, Chile.

El uso de dispositivos transcatéter para cierre de defectos paravalvulares, cierre de orejuela izquierda y reparación mitral se ha hecho más frecuente en los últimos años ${ }^{1}$. Esto ha convertido a la ecocardiografía transesofágica tridimensional en una herramienta de gran utilidad para la selección, guía durante el procedimiento y posterior seguimiento de los pacientes que se someten a este tipo de intervención ${ }^{2}$. A continuación se muestran tres imágenes de procedimientos percutáneos cardíacos asistidos mediante ecocardiografía transesofágica tridimensional.

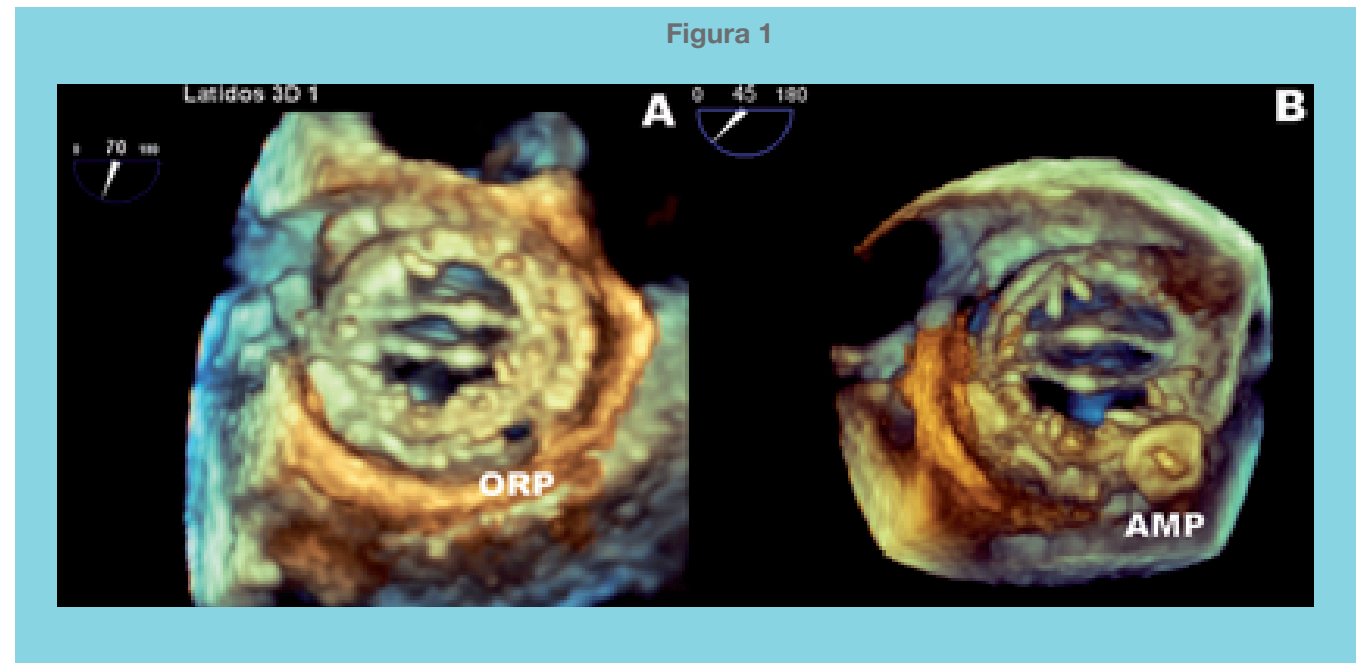

A.

Visión transesofágica tridimensional de prótesis mecánica de doble hemidisco en posición mitral explorada desde la aurícula izquierda (imagen en diástole). Se observa la dehiscencia periprotésica que determina el orificio regurgitante paravalvular (ORP) en situación postero-medial.

B. Visión transesofágica tridimensional del mismo paciente posterior al procedimiento percutáneo de cierre de la dehiscencia periprotésica. Se observa dispositivo Amplatzer (AMP) que ocluye el ORP.

Correspondencia

Doctor Carles Paré

cpare@clinic.ub.es

Jefe Sección Imagen Cardíaca

Hospital Clínic

Barcelona, España. 


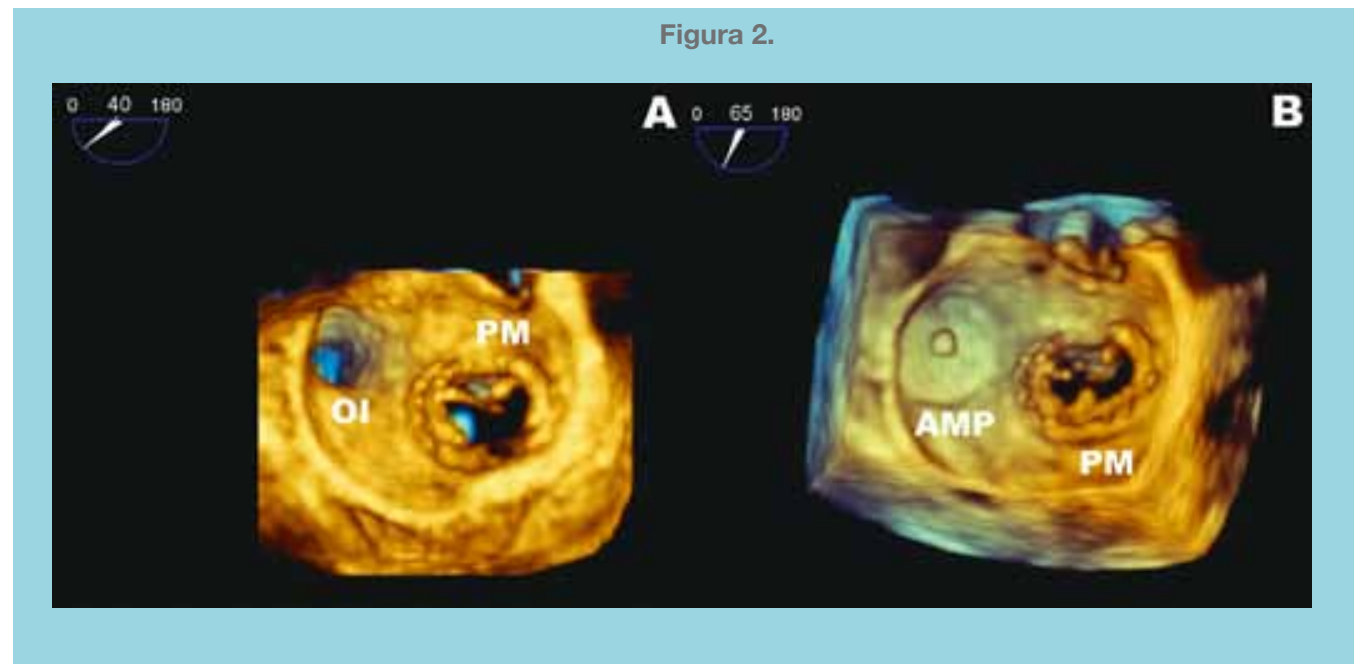

A. Visión transesofágica tridimensional de orejuela izquierda (OI) y prótesis mitral (PM) biológica vistas desde la aurícula izquierda.

B. Visión transesofágica tridimensional post-procedimiento percutáneo, donde se observa el dispositivo Amplatzer que ocluye el orificio de entrada de la OI.

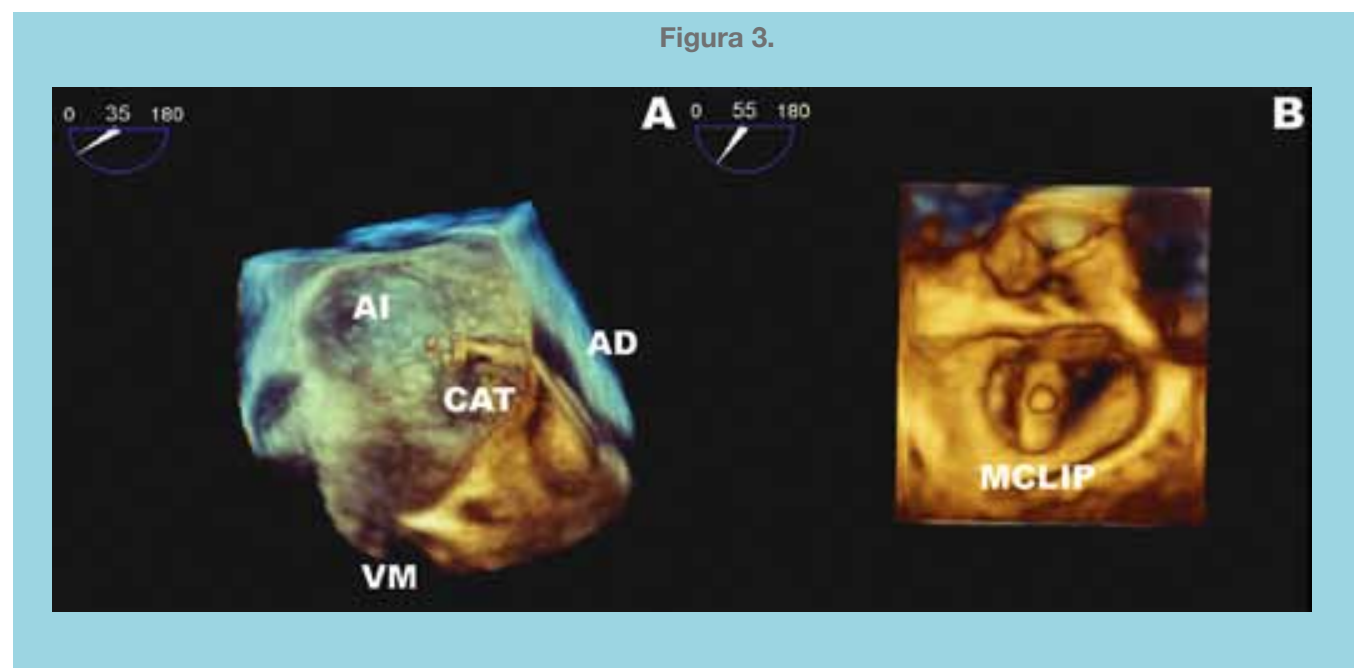

A. Visión transesofágica tridimensional durante la guía ecocardiográfica de reparación percutánea de insuficiencia mitral con dispositivo MitraClip (MCLIP). Se observa paso del catéter (CAT) desde aurícula derecha (AD) hacia aurícula izquierda (AI) a través del tabique interauricular. Abreviaciones, Ao:aorta; VM: válvula mitral.

B. Visión tranesogágica tridimensional de la válvula mitral vista desde la AI. Se observa dispositivo MitraClip posicionado entre segmentos A2 y $P 2$ de válvula mitral.

\section{Referencias:}

1. SILVESTRY FE, KERBER RE, BROOK MM, CARROLL JD, EBERMAN KM, GOLDSTEIN SA, et al. Echocardiography-guided interventions. J Am Soc Echocardiogr 2009;22:213-
31.

2. LANG R, BADANO L, TSANG W, ADAMS D, AGRICOLA E, BUCK T, et al. EAE/ASE Recommendations for image adquisition and display using three-dimensional echocardiography. J Am Soc Echocardiography 2012;25:3-46. 